\title{
MÁS SOBRE LA CONVERSIÓN DE SOR JUANA
}

El cambio radical que Sor Juana Inés de la Cruz dio a su vida en 1693 o a principios de 1694 -algunos meses antes de su muerteplantea problemas sumamente espinosos: el hecho es extraño y los datos son muy escasos. Sobre las circunstancias y las relaciones entre Sor Juana y la autoridad eclesiástica sabemos algo más, pero nuestras fuentes primarias están bastante dispersas y no son siempre fáciles de interpretar.

Ya se ha escrito mucho sobre este tema. El caso más ilustre es el de Octavio Paz, quien acaba de dedicar al problema la última parte de su "ensayo de restitución" en Sor Juana Inés de la Cruz o las trampas de la $f e$. Nos atrevemos a añadir algunas páginas a un legajo ya voluminoso. El motivo no es haber encontrado la clave del misterio, solamente queremos comentar algunos textos de procedencia eclesiástica novohispana relacionados con el asunto. Uno de ellos, escrito en Antequera (otro nombre de Oaxaca) a mediados del año 1691, es decir, después de la redacción de la Respuesta a Sor Filotea, y publicado en Puebla a fines del mismo año, se encuentra en unas cuantas bibliotecas, y apenas se le ha tomado en cuenta hasta hoy. En particular, está ausente de la valiosa recopilación de textos sobre Sor Juana realizada por Francisco de La Maza y revisada por Elias Trabulse: Sor Juana Inés de la Cruz ante la historia (UAM, México, 1980). Se trata de la dedicatoria a la primera edición de los Villancicos a Santa Catarina, firmada por el Dr. Jacinto de Lahedesa Verastegui, "chantre de la Catedral de Oaxaca, comisario del Santo Oficio de la Inquisición y su calificador". Se dirige al R.P.M. fray Francisco de Reyna, "Provincial de la Provincia de San Hipólito Mártir de dicha ciudad"'.

' Fue posibie ieer este texto en ia John Carter Brown Library de Brown University, Providence, R. I., Estados Unidos. La serie de villancicos es la séptima de una colección cuya signatura es B $69 \mathrm{G} 643 \mathrm{v}$. La dedicatoria no tiene paginación. El conjunto fue publicado en Puebla, "en la imprenta de Diego Fernández de León", a fines de I69I (la licencia fue firmada en septiembre). Agradecemos la ayuda de Everett C. Wilkie Jr."bibliographer" de aquella "Providencia" de estudiosos. 
Bastante conocida y celebrada es la amplitud de criterio - y a veces la inteligencia y el buen gusto literario - con que el clero peninsular, entre 1689 y 1693, acogió la publicación de las principales obras de Sor Juana. Un número respetable de doctores admiraron su genio poético, y también aceptaron la intromisión de la monja en su propio coto cerrado: la teología. Como botón de muestra, vale la pena citar aquí dos observaciones del censor Juan Navarro Vélez, calificador del Santo Oficio de la Inquisición de Sevilla. La primera enjuicia los autos sacramentales.

... los Autos de la Madre Juana son cabalmente perfectos, y en todo cumple con lo que debe a las leyes del Teatro, a la verdad de la Religión, a la pureza de la más sana doctrina, y a la Soberana Majestad del Misterio. Y si cumplir con tanto fuera elogio muy crecido aun para un hombre muy grande: ¿qué será cumplir con todo el ingenio y el estudio de una mujer?

La otra se refiere a la Crítica del sermón de Vieira:

Con este Campeón que pusiera miedo aun al más alentado, sale a la Palestra, y en todo se porta verdaderamente bizarra: en las cortesanías discretas con que le trata; en las ventajas grandes que, liberal y modesta, le cede; en lo a tenta, que le venera; en lo ingeniosa, que le contradice; en lo sutil, que le arguye; en lo docta, que se le opone; y en lo esforzada, que aspira a quitarle o a competirle la palma. Y en todo con tan docto primor, que estoy cierto que si el mismo Autor hubiera visto este papel, no sólo le coronara de merecidos elogios, y fuera ésta su más gloriosa recomendación, sino que, o de cortesano, o de convencido, cediera el triunfo y el laurel a la competidora ingeniosa, y la confesara vencedora en lo que le impugna, y en lo que le añade ${ }^{2}$.

Esta reacción del clero español es realmente ejemplar, pero ¿no pudieron ser contraproducentes en México tantos elogios? Parece que, si cruzamos el Atlántico, el panorama cambia mucho. Oigamos a la propia Sor Juana en la Respuesta:

...entre las llores de las acla maciones se han despertado tales áspides de emulaciones y persecuciones cuantas no podré contar...La - en mí dos veces infeliz - habilidad de hacer versos, aunque fuesen sagrados, ¿qué pesadumbres no me han dado, o cuáles no me han dejado de dar? ... acercarme al fuego de la persecución, al crisol del tormento (passim).

Seguramente, gran parte de estos impugnadores eran eclesiásticos, pero hay que tener cuidado de no exagerar el alcance de esas "persecu-

2 Transcribimos de una de las ediciones de Barcelona 1693 del Segundo volumen de las obras de Sor Juana Inés de la Cruz, publicado por primera vez en Sevilla en 1692. Se puede leer el texto entero y otros elogios más en Sor Juana Inés de la Cruz ante la historia, pp. 85 ss. 
ciones". Varios pasajes de la Respuesta nos prueban que Sor Juana no tiene miedo cuand o la escribe. No hablaría de su temor a la Inquisición si éste fuera realmente serio; no mencionaría los tres meses de prohibición de los estudios que tuvo que sufrir si sospechara que se pudieran repetir; no compararía sus persecuciones con las de Cristo si pensara que, en aquel preciso momento, el poder eclesiástico exigía de ella especial humildad y obediencia.

Según parece, ninguno de los folletos escritos en aquel tiempo contra la monja, o en defensa suya, que los hubo también, se ha conservado. Atengámonos entonces a los documentos asequibles. El único que es realmente muy conocido es la Carta de Sor Filotea, firmada el 25 de noviembre de 1690 por su verdadero autor, D. Manuel Fernández de Santa Cruz, obispo de Puebla. El tono y la argumentación de estas páginas motivaron la firme aunque muy respetuosa Respuesta de la monja, el $\mathrm{I}^{\circ}$ de marzo de 1691. La Carta ha sido analizada muchas veces, y lo seguirá siendo. Las dosis de benevolencia y de malevolencia - intencionada o no-contenidas en ella son un tema de discusión. Lo único cierto es que el obispo pide a Sor Juana que renuncie a las letras "humanas" para dedicarse a las letras "divinas". Habla en nombre de la piedad, no en nombre del oscurantismo antifeminista ${ }^{3}$.

Otro texto conocido desde hace mucho tiempo, pero menos citado de lo que merece, es La fineza mayor, sermón panegyrico del presbítero Francisco-Javier Palavicino, predicado en el convento de San Jerónimo en 1691 y publicado el mismo año en México ${ }^{4}$. El sermón va dedicado a las monjas del convento. Se mencionan los nombres de las que tienen un cargo, entre ellas la "contadora" Sor Juana Inés de la Cruz. Según el autor, la mayor fineza de Cristo es "sacramentarse ocultándose". Unas páginas a modo de prólogo presentan esta idea como una tesis personal completamente independiente de la crítica de Sor Juana al esquema de Vieira: "ni sigo, ni impugno; sino, admirándome de tan profundo ingenio, yo, aunque minimo entre todos, doy mi solución a la duda". Acaba de alabar a la monja en estos términos:

El más llorido ingenio de este feliz siglo, la Minerva de la América, cuyas obras han conseguido generales aclamaciones y obsequiosas, si debidas estimaciones, hasta de los mayores ingenios de Europa, y de los que se persuaden tener buen gusto en sus objetos; y lo que es más, de los genios opuestos sólo por hallarse ëste grande ingenio himitado con la cortapisa de mujeril. Esta, digo, señora, la Madre Juana Inés de la Cruz, profesa

${ }^{3}$ Recordemos que la Carta de Sor Filotea encabeza la edición de un texto de polémica religiosa, la Carta Atenagórica, donde Sor Juana refuta al predicador Antonio Vieira sobre el tema de las Finezas de Cristo. El obispo la publicó sin informar a la autora.

${ }^{4}$ Se conserva en la Biblioteca Nacional de México (1267 LAF). Octavio Paz, que ha utilizado otra versión, da la fecha del sermón: 10 de marzo. 
etc..., parto fecundísimo del más divinizado entendimiento del Jerónimo Júpiter...

El estilo de estas líneas es muy de la época, tal vez demasiado, pero nos enseña que el éxito de las primeras publicaciones de Sor Juana en España halagaba el orgullo de los novohispanos y servía para rebatir el antifeminismo de una parte por lo menos del clero. Nos enseña también que en la arquidiócesis de México era posible que un sacerdote publicara un elogio de Sor Juana.

Un panegírico mucho más largo es la dedicatoria de seis páginas que el Dr. Jacinto de Lahedesa publicó en Puebla. En 1952, Alfonso Méndez Planearte citó algunas partes de este texto en una nota del tomo 2 de las Obras completas: "Prodigio de Naturaleza..., Prototipo de las ciencias... Oráculo de toda la América... Mujer fuerte..., singular entre todas. . " ${ }^{6}$ El incansable editor de la jerónima proyectaba reproducir el texto entero en el tomo 4 que, finalmente, no pudo realizar él mismo. En realidad, la edición conjunta de los Villancicos a Santa Catarina y de esta dedicatoria es un hecho de cierta importancia tanto por el contenido como por la fecha y el lugar de publicación.

Sor Juana cuidó mucho la composición de aquellos poemas que celebraban a una mujer que había logrado convencer con su elocuencia a "todos los sabios de Egipto"; algunos son unas joyas. Ciertos versos contienen además una reivindicación feminista más atrevida que la de Respuesta a Sor Filotea:

Estudia, arguye y enseña, y es de la Iglesia servicio: que no la quiere ignorante El que racional la hizo. ¿Víctor, víctor! ${ }^{7}$

El texto anterior reclamaba tan sólo el derecho a enseñar "privadamente". En éste, Sor Juana contradice implícitamente al mismísimo San Pablo, de la Primera epístola a los Corintios (XIV, 34): "Las mujeres cállense en las asambleas, porque no les toca a ellas hablar sino vivir sujetas”. ¿Es que quiere la monja elevar el tono de la polémica? Es muy poco probable, ya que el cambio de lenguaje se explica perfectamente por el cambio de género literario. En unos villancicos cantados ante el pueblo un día de fiesta, es posible introducir - entre veras y burlas - ciertas cosas que serían inconcebibles en un alegato dirigido a un obispo ${ }^{8}$.

Pai.avicino, op. cit., pp. 2-3.

"Obras completas, t. 2, p. 431.

Villancico VI, vv. 34-38, Obras completas, t. 2, p. 171. Se gritaba "Víctor" a los nuevos doctores.

* Sor Juana introduce quiquiriquís en la fiesta de San Pedro, lo que viene a ser 
Ahora bien, aunque a su manera, la dedicatoria duplica el mensaje de los versos. Es evidente que D. Jacinto no iba a declarar que Sor Juana discrepaba de San Pablo y que tenía toda la razón. Por ello no alude en absoluto al contenido de los versos, sino que encuentra una hermosa cita del francés Hugo de San Víctor que justifica la vocación intelectual de la jerónima: "Per scientiam itur ad disciplinam, per disciplinam ad bonitatem, per bonitatem ad beatitudinem"; sobre todo, gasta gran parte de su elocuencia en comparar a Sor Juana sucesivamente con cada una de las Sibilas, aquellas famosas profetisas de la Antiguiedad pagana a quienes muchos autores cristianos, incluso Sor Juana, consideraban como anunciadoras de la verdadera $\mathrm{fe}^{10}$. ¿Quién puede hablar con más autoridad que una Sibila? Realmente, esta asimilación viene a ser la reivindicación de un magisterio específico para la monja. Y dice el autor: "su saber es antorcha que reparte rayos sin que jamás pueda extinguirse tanta llama...; aprehendan pues de esta luz que no se acaba, antes se enciende cuando más se agota".

Estas líneas las firma un miembro de la Inquisición; aunque lejana, Antequera-Oaxaca era entonces la tercera o la cuarta ciudad de la Nueva España; el texto va dirigido a un provincial; los poemas se cantan el mismo año en la catedral de la ciudad, forzosamente con la aprobación del obispo y del cabildo eclesiástico; firma la licencia de publicar D. Jerónimo de Luna, vicario general de Puebla (3 de septiembre de 1691); hay aprobación del Ldo. D. Antonio Delgado y Buenrostro: contamos con una pequeña lista de amigos provincianos de Sor Juana para completar la de la capital. Pero no olvidemos el nombre principal de la lista, aunque no aparezca en ningún lugar: el propio D. Manuel Fernández de Santa Cruz, nuestra Sor Filotea de marras. Si los villancicos se cantan en una ciudad lejana, es porque la monja y sus amigos estiman que no es posible -o no es adecuado-cantarlos en la capital. Como Oaxaca no tiene imprenta, Puebla es el único lugar posible para la publicación de un folleto, pero dicha impresión depende del visto bueno del obispo. Así constatamos que, a unas semanas de recibir la famosa Respuesta, en vez de enfadarse, D. Manuel decidé o acepta la publicación de un texto más atrevido que el anterior.

Probable - no seguro, desde luego - es que el mismo D. Manuel lo

mentar la soga en casa del ahorcado (ibid., p. 59); pide que las limosnas juntadas por los padres mercedarios sirvan para rescatar esclavos negros (ibid., p. 40); afirma que "el vientre de María/es mucho mejor que el cielo"(ibid., p. 4). El último texto es de 1676; ios otros dos de 1677. Sería posibie aducir más ejemplos.

" "Por la ciencia se consigue la formación de la mente y del carácter, por ésta se consigue la bondad, por ésta última la felicidad (o la beatitud eterna)".

${ }^{10}$ Conocida es la referencia a las Sibilas en el himno "Dies irae". En la Respuesta a Sor Filotea, Sor Juana dice: "las Sibilas, elegidas de Dios para profetizar los principales misterios de nuestra Fe", 11. 861-862. 
haya dirigido todo. Era muy amigo de su colega de Oaxaca, el Dr. Isidoro de Sariñana. Éste acababa de fundar, cerca de la famosa iglesia de la Virgen de la Soledad, un convento de agustinas recoletas a imitación del de Santa Mónica que D. Manuel había fundado en Puebla. Las gestiones habían sido largas y difíciles, y D. Manuel había escrito a la Corte para apoyar el proyecto. Al fin, en 1690, él mismo escogió a las cinco monjas de Santa Mónica que salieron para Oaxaca como fundadoras, y las acompañó hasta la frontera de las dos dióce$\operatorname{sis}^{11}$. D. Isidoro pudo haber conocido a Sor Juana cuando era chantre de la catedral de México; tal vez él mismo haya tenido la iniciativa de encargarle villancicos allí, por ejemplo, en 1677. Una alianza entre a mbos prelados es bastante verosímil. Cualesquiera que hayan sido las circunstancias exactas, parece que ya podemos salvar a $\mathrm{D}$. Manuel de la acusación de haber abandonado a Sor Juana después de protegerla. Se trata de un verdadero error judicial. ¿Cómo habría podido defender a la monja de manera más abierta? Hubiera sido contraproducente. No le era posible inmiscuirse en los asuntos de una diócesis vecina. Por eso había firmado "Sor Filotea" su primera intervención pública. Juzgó imprudente publicar la Respuesta pero la conservó para la posteridad. Estamos casi seguros de que la difundió en copias manuscritas: el número de errores de latín en el primer texto impreso de 1700 en Madrid es realmente poco común. Se debe probablemente a una cadena de copias: los escribientes sabían español, pero no sabían latín. Difundir villancicos de la monja era lícito, porque era un género literario que nadie tomaba en serio: la catedral de Puebla había encargado por lo menos tres series a Sor Juana entre 1689 y 1690 . No era una "novedad" que en Oaxaca se cantara una serie más en 1691. Si nuestra hipótesis es exacta, la jerónima mandó sus poemas a D. Manuel, según lo anunciaba al fin de la Respuesta: "Si algunas cosillas escribiere, siempre irán a buscar el sagrado de vuestras plantas" ${ }^{12}$, y él tuvo el mérito de concederle este desagravio por los pasajes demasiado duros de su propia carta.

Desde luego, queda en pie el problema principal. El destino de Sor Juana se decidía en México, no en Oaxaca, ni en Puebla. Quien tenía poder sobre ella era su arzobispo e, indirectamente, el a migo o consejero del arzobispo, su ex-confesor el jesuíta Antonio Núñez de Miran$\mathrm{da}^{13}$. Parece cierto que, desde el ingreso de Jùana en el convento, la

1 Cf. Miguel de Torres, Dechado de príncipes eclesiásticos, Puebla?, 1714, cap. xxxII ss. El libro es una biografía de D. Manuel que había muerto en 1699, después de veintitrés años de pontificado en la sede de Puebla-Tlaxcala. El tono es hagiográfico, pero el autor proporciona el texto de bastantes documentos of iciales. D. Isidoro de Sariñana y Medina había nacido en México en una familia modesta. Pudo estudiar gracias a una beca. Fue obispo de Oaxaca de 1683 a 1696.

${ }_{12}$ Respuesta, Obras completas, t. 4, p. 474, 11. 1406-1407.

13 Por su austeridad, ciencia, elocuencia, etc., D. Antonio gozaba de una posición elevadísima en México. Dirigía una congregación integrada por personas de rango 
autoridad eclesiástica se las había arreglado para que la "gloria" literaria e intelectual de ella se mantuviera dentro de ciertos límites: podía leer y escribir pero no se representaban sus obras de teatro en público, y se editaban solamente sus textos de circunstancia. Un convenio implícito de este tipo vale más que un escándalo. Desde 1681, el arzobispo es D. Francisco Aguiar y Seijas. Hacia 1690, ve llegar tomos de las obras de la poetisa impresos en España; tal vez como eco a esta nueva gloria peninsula1, D. Francisco da su venia para la publicación, ese mismo año, del auto sacramental El divino Narciso: es la edición príncipe, impresa en la misma ciudad de Sor Juana.

Muchos autores opinan que a partir del año 1692, poco más o menos, la situación de la monja sufre un cambio radical. Una coacción progresiva e implacable del clero --sobre todo, del arzobispo- la reduce al silencio y a la soledad. Como se trata de una presión de tipo moral más bien que de tipo administrativo, es normal que no haya dejado ninguna huella escrita.

Inmediatamente surge un argumento contra esta tesis: ¿cómo puede ser que no conservemos ningún comentario de un hecho tan sorprendente? ¿Cómo no se queja la ciudad de México que ha perdido a su musa? ¿Cómo no protestan los numerosos amigos de Sor Juana? Sobre todo, ¿cómo no celebra el poder eclesiástico una victoria tan sonada con algunos libros edificantes? Y en seguida surge otra pregunta: ¿se dan más ejemplos de la tiranía de D. Francisco?

Para responder, disponemos de dos fuentes: el conocido Diario de Antonio de Robles $^{14}$ y la breve biografía de Aguiar y Seijas que escribió José de Lezamis, cura de la catedral, en 1699, un año después de la muerte del arzobispo ${ }^{15}$. Hasta cierto punto, ta mbién es aleccionador el "sermón para conventos", firmado por Raimundo Lumbier, pero editado por D. Francisco y D. Antonio en la época de la renuncia de Sor Juana ${ }^{16}$. En junio de 1687, nos dice Robles, "Su Illma. mandó

social bastante alto: oidores, etc. Se ignoran la fecha y circunstancias del abandono de Sor Jua na por su confesor, a quien volvió a lla mar en el momento de su conversión. En cuanto a su amistad con D. Francisco Aguiar y Seijas, véase infra, nota 16.

14 Diario de sucesos notables (1665-1703), ed. Antonio Castro Leal, 3 tomos, Porrúa, México, 1946. Robles no es un clérigo.

${ }_{15}$ Leza mis escribió una Vida del Apóstol Santiago, impreso por Doña María de Benavides, México 1699. El libro va dedicado al cabildo y deán de Santiago de Compostela. El contenido de esta dedicatoria es la biografía del difunto D. Francisco. Tal vez existan otras ediciones.

${ }_{16}$ Destierro de ignorancias. Fragmento áureo, Preciossisimo de la juiciosa erudición Moral del Doctíssimo y Religiossisimo P. M. Fr. Raymundo Lumbier. Dalo a la estampa por orden y con mandato de su llustríssima el Sr. Arz. en obsequio de las Sras. Religiosas, alibio de sus PP. Capellanes y consuelo de todos sus Confessores El padre prefecto de la Puríssima [Núñez] y su lllma. concede 40 días de Indulgencia a qualquiera persona de los interesados en la materia por cada vez que leyere algún Párrapho destos, México, 1694. Es una $2^{a}$ edición. La licencia del virrey y del arzobispo es del 30 de julio de 1694 . No conocemos la fecha de la $1^{a}$ edición. La $2^{a}$ está en la Biblioteca Nacional de México. 
con censura echar todos los perros de los conventos y se ejecutó". Lezamis alaba el.celo del arzobispo contra las galas, los toros, las comedias, los gallos y el juego. También quería "acabar con los libros profanos, de comedias y otros y repartir libros devotos" ${ }^{17}$. En las librerías de México los trocaba por libros piadosos y compraba a veces todas las entradas de una pelea de gallos para que nadie la viera. El Destierro de ignorancias de Lumbier contiene frases fulminantes contra las "devociones" de monjas, los "repetidos papeles de amores", y la indulgencia acostumbrada en este terreno: "Tampoco les excusará del pecado mortal el que algún confesor no docto" las perdone ${ }^{18}$. Pero si D. Francisco hubiera decidido acabar con los flirteos de locutorio, este hecho inaudito hubiera dejado alguna huella, por ejemplo una reseña de Antonio de Robles. Según los testimonios que tenemos entre manos, las palabras del prelado eran durísimas, pero sus actos eran mucho más blandos. ¿Qué podía él contra costumbres inveteradas? Aleccionadora es la portada de Destierro de ignorancias: "su Illma. concede 40 días de Indulgencia a cualquiera persona de las interesadas en la materia por cada vez que leyere algún párrafo déstos". Ni siquiera reserva sus indulgencias a las personas que observen sus mandatos. Realmente, este tigre es un tigre de papel. Parece casi cierto que durante los años de D. Francisco en la sede de México, todo siguió igual, o casi: el concubinato de muchos feligreses y de cierta parte del clero, y las profanidades en los conventos.

Profundizando un poco más en la lectura de Lezamis, cabría preguntarse si el tigre de papel era realmente un tigre. La fama que dejó fue la de un señor muy hosco y malhumorado que huía de las mujeres como si fueran el mismo demonio, también la de un santo varón que gastaba casi todos los cuantiosos ingresos de su cargo en limosnas. Aparte de eso, no parece haber sido un gran arzobispo, sobre todo si lo comparamos con el obispo de Puebla que fundó un convento "observante" y, hecho más notable, que consiguió proteger a su grey del hambre de 1692, manteniendo el precio del maíz a "ocho pesos carga", cuidando él mismo de abastecer las alhóndigas y negando al virrey, mediante argucias jurídicas, el derecho de sustraer este grano para la capital $^{19}$. En México, hubo hambre y motín. La actitud de D. Francisco no fue cobarde, pero tampoco especialmente lúcida. Quienes apaciguaron a los amotinados fueron algunos frailes y clérigos, no el mismo arzobispo.

Como Lezamis había sido el confesor de su biografiado, pudo darnos la clave del personaje: D. Francisco era un mártir de la castidad. Si huía de las mujeres, no era por una opción ideológica, sino por una sencilla necesidad higiénica: huir del peligro era su mejor defensa. Su

17 P.G. (paginación por letras).

is Ibid., p. 41

is Torres, Dechado..., cap. 40-41. 
continuado martirio bastaba para hacer su condición penosa para el personal del palacio, no forzosamente para infundirle decisiones crueles. Desde luego, antes y después del Dr. Freud, la castidad eclesiástica ha traído como resultado en muchos casos el desprecio o el odio hacia las mujeres. Sin embargo, después de lamentar esta forma algo irrisoria de heroísmo del infeliz arzobispo, se debe intentar juzgarlo según sus actos concretos, y no según*ideas preconcebidas. Ahora bien, no hay que exagerar su neurosis antifeminista. Amenazaba con quitar las baldosas del umbral de su palacio si las pisaba una mujer, pero parece que no lo hizo nunca. Decía eso para enfatizar la distancia que quería establecer entre el segundo sexo y su persona. Si suprimía, en la medida de lo posible, sus visitas a Palacio, cumplía con lo imprescindible. Funciones como el bautizo y la confirmación del hijo de un virrey debían de ser pruebas especialmente penosas. No nos dice la crónica si las damas preparaban cuidadosamente en su tocador la tortura de su prelado. Por otra parte, gastó innumerables semanas en cansadas visitas pastorales por los pueblos lejanos. Nunca se dijo que se hubiera abstenido de confirmar a las mujeres, ni que sus limosnas se hubieran reservado exclusivamente a los varones. Un aspecto humano de su personalidad es la

cortesía con que trataba a todos...: a cualquiera persona aunque fuese de mediano porte le daba asiento, y le trataba de usted, y aun a los Meztizos y Mulatos, y aun a los Indios solía tratar de Vmd. ${ }^{20}$

Era capaz de admirar a las mujeres, porque fomentó el culto de Santa Rosa de Lima, a quien se acababa de canonizar. No condenaba especialmente las actividades literarias: no aprovechó la publicación del Destierro de ignorancias para añadir algún capítulo contra las letras en los conventos. De sus relaciones con Sor Juana, sabemos muy poco a ciencia cierta: primero, el hecho de haber inspirado la venta de sus libros y preseas en favor de los pobres; segundo, otro hecho anterior y menos conocido, que es el permiso de comprar su "celda" en febrero de 1692. Esto no iba bien con el voto monástico de pobreza. Se necesitaba una dispensa del prelado. El hecho era muy corriente, pero en caso de tener inquina contra Sor Juana, D. Francisco hubiera podido aprovechar su posición para dar largas al asunto. Su benevolencia es doblemente interesante, primero porque el acta es posterior a la redacción de la Respuesta y a la publicación de los villancicos a Santa Catarina; segundo, porque le quita de encima al arzobispo la sospecha de haber querido despojar a aquella débil mujer de todos sus bienes en provecho de los pobres. Una "celda"en San Jerónimo era un verdadero piso de varias habitaciones. Como, según parece, no existe ningún documento sỏbre una venta posterior, esto quiere decir que la

${ }^{20}$ Lezamis, p. c. 
mayor parte de la fortuna de la "Décima Musa" se conservó en la familia ${ }^{21}$.

En síntesis, si nos faltan pruebas de persecución serias contra Sor Juana, tenemos algunas pruebas de lo contrario. Éstas tal vez no nos basten para una conclusión rotunda; nos bastan, sin embargo, para formular dudas sobre las causas de la conversión de la poetisa. Antes de acabar esta reseña de documentos, queremos indicar una pista para futuras investigaciones. Varios autores han hablado del clima de penitencia que se había apoderado de México después del gran motín de 1692. Apoya esta suposición una frase de Antonio de Robles:

Las causas de este estrago se discurren ser nuestras culpas que quiso Dios castigar, tomando por instrumento el más débil y flaco como es el de unos miserables indios, desnudos, desprevenidos y desarmados, como en otros tiempos lo ha hecho su Divina Majestad como parece por historias divinas y humanas ${ }^{22}$.

No es imposible saber más sobre este tema: en la Biblioteca Nacional de México y en unos centros como la Hispanic Society de Nueva York, se conservan muchísimos sermones de la época. Ciñéndose a la segunda mitad del año de 1692, sería posible gracias a ellos restituir el ambiente moral de la ciudad, y valorar hasta cierto punto la influencia de este ambiente sobre el cambio de vida de Sor Juana ${ }^{23}$, pero sin confundir lo que es prédica moral con lo que puede ser coacción y amenaza ${ }^{24}$.

\section{Marie-Cécile Bénassy-Berling}

Université de Paris 111-Sorbonne Nouvelle.

2 Ya el año anterior, Sor Juana había invertido otra cantidad de dinero: "Censo sobre 1400 pesos asegurado en fincas del convento de San Jerónimo que se establece a favor de Sor Juana Inés de la Cruz", 24 de marzo de 1691 (cf. Enrique A. Cervantes, Testamento de S.J.I. de la C. y'otros documentos, México 1949, p. 38).

22 Tomo 3, p. 97, 8 de junio de 1692.

Véase nuestra tesis Humanisme et religion chez Sor Juana Inés de la Cruz. La femme et la culture au xviit siècle, Publications de la Sorbonne, Éditions Hispaniques, Paris, 1982. Traducción española realizada por la Universidad Nacional Autónoma de México.

24 Después de impresas estás páginas, nos llega el texto completo de la Autodefensa espiritual recién descubierta y casi seguramente auténtica. Nos confirma la fecha aproximada de la ruptura entre Sor Juana y su confesor. Posteriormente la publicación de obras de Sor Juana en 1689-1692 le habrá disgustado sobremanera, pero era también un hombre prudente, y seguimos pensando que un acto de persecución inspirado al arzobispo por D. Antonio hubiera armado un escándalo. Y cabe ver un anuncio del porvenir en: "el privarme yo de todo aquello que me puede dar gusto, aunque muy lícito, es bueno que y'o lo haga por mortificarme, cuando y'o quiera hacer penitencia". La monja aparece como un ejemplo prodigioso de entereza espiritual. Tuvo confesores, que no directores. 